\title{
The importance of thought in medical practice
}

For several centuries, good physicians generated aspects related to thought in order to achieve a better health. Galen was a great Greek master later stationed in Rome, in a time when severe pandemics took place. He was a physician and a philosopher and used to talk to physicians by approaching and telling them to always have the need to think when facing a disease.

Over the years, in the $17^{\text {th }}$ century, physicians started generating thoughts in groups; this way, something extremely important in health care was initially achieved. It was an opportunity for physicians to work together and generate their thoughts, especially in the presence of patients with difficult and severe disorders. This increased progressively until they were able to address different health problems.

Given the many changes that have taken place in the field of medicine since the 1950s, and the fact that these changes have occurred increasingly rapidly, thought unfortunately no longer resembles what physicians used to do in the past. Currently, most physicians behave in a different manner: they see patients in just a few minutes, use computers a lot, and have a broader approach to technology, which increases strongly and without slowing down. In addition, physicians work in the presence of commoditization, which has overwhelmed medicine with inadequate factors; therefore, we are contributing to a loss of ethical and moral values in our profession.

Thinking is an action governed by rules, usually riddled with stereotypes which are not subject to reflection and is not generally present in our consciousness. It is indispensable to reflect so that we may act in an adequate manner, because the consciousness of thought is our only weapon against nonsense and frustration.

However, medical thought has become much more complex, especially due to the changes in patient care. Other effects take place in the differences observed in health care systems, leaving medical science knowledge aside and failing to approach humanism. The complexity of medicine may now exceed our capacity; therefore, we should generate the most adequate actions for patient care.

In the times we are living, it is common to hear physicians say that they have no time to think in their daily routine. This is exactly what they should not do. In addition, these times call for deep thinking, now more urgently than ever, and this will lead them to become intolerant of uncertainty. To prevent this, it is absolutely imperative to cultivate a critical attitude, significantly learn the actions we implement, and take into account that we are capable of errors. If many of our actions keep having errors, they will become more frequent and riskier. If so, uncertainty will often be silenced under the embellishments of professionalism and other resources that lead physicians to forget about considering this reality.

Information may be inadequate, and it is indispensable that we test our ability to think actively, as good physicians do. They should teach younger individuals, both those who are studying in universities and those who are already undertaking a residency program. If this is not the case, many young physicians usually end up reading only the abstracts of articles. This is deplorable, and physicians should know that these actions cannot take place at all times because, many times, they are highly inadequate and dangerous. Medical decisions should lead to several adequate actions through thought and also with the help of colleagues who have a broader knowledge.

The medical profession is also going through rapid social changes, in addition to the importance of scientific and technological foundations in medical practice. By means of our actions, we should increasingly generate thought.

All physicians should know that thinking is regulated by rules with automatic short circuits and stereotypes, but most fail to reflect on what their patients tell them. Reflection leads us to thought, and our consciousness should be consistent with ethics.

In future years, science will continue accumulating actions that differ from current ones; therefore, it would be adequate to have better physicians based on patients' conditions and needs. This could be achieved if medical schools taught the advances made in health care; and future physicians will require to develop thoughts suitable to all the activities they have to do.

Cognitive skills are exclusive to human beings thanks to their ability to develop knowledge. To understand other actions carried out by physicians, it is important to know how to 
generate what is known as narrative thought. Many physicians conduct narrative thought, which was the main core of the art of medicine until the $19^{\text {th }}$ century. It would be of utmost importance to have narrative thought back because it would be really valuable in medical activity.

We usually approach many challenges related to highly complicated medical actions; therefore, we are very unlikely to find simple solutions. When asking physicians to think in these situations, they say that they work very hard, but they are actually working inadequately. Among other aspects, it is not surprising that we make many wrong decisions and that, in the midst of the many actions we carry out, diagnostic errors occur, which will certainly increase significantly.

Alberto Agrest, M.D., was an excellent physician who left us with well-known phrases, such as "Most likely, a quantitative truth is hiding a qualitative falsehood. The problem with numbers is that they generate a feeling of certainty; something that medical reality does not admit; it is essential to learn to tolerate uncertainty. In the field of medicine, certainty is a certificate of ignorance or folly."
Finally, we should bear in mind that $21^{\text {st }}$ century medicine will require critical changes in how we conceive thinking, the structure of medical education, research, and humanism.

José María Ceriani Cernadas

Editor-in-chief

http: / / dx.doi.org/10.5546/ aap.2021.eng.74

To cite: Ceriani Cernadas JM. The importance of thought in medical practice. Arch Argent Pediatr 2021;119(2):74-75.

\section{REFERENCES}

- Obermeyer Z, Lee TH. Lost in Thought - The Limits of the Human Mind and the Future of Medicine NEJM September 28, 2017.

- Naylor CD. The evolution of medical schools of thought. Healthy tensions., JAMA Posted online February 24, 2020.

- DeLeon J. Enseñando a pensar a los Estudiantes de Medicina: El Pensamiento Narrativo, Mecanístico y Matemático. Actas Españolas de Psiquiatría 2018;46 (4): 133-145.

- Casino G. Pensamiento científico. IntraMed / Fundación Esteve; 2018. 